\title{
STUDYING EDUCATIONAL COMPUTING PROJECTS
}

\author{
Challenges and Opportunities
}

\author{
Mary E. Hopper \\ Lesley University, USA \\ E-mail: mhopper@mail.lesley.edu
}

Abstract: $\quad$ This paper describes how a long-term project has evolved from a qualitative research study carried out in the early 1990s to the point of transition where it is today. The long-term goal of the project has been to improve the viability of educational computing projects by identifying and disseminating effective and sustainable strategies. The initial study took place between the years 19901993. Information from interviews with 19 key participants and supplemental documents were used to explore the educational, technical and organizational contexts of a number of projects. In each project, attempts to reach unique discipline and learner oriented goals afforded by new computing capabilities led to unforeseen technical challenges that became intertwined with issues related to traditional organizational structures. Limitations encountered in the original study's methodology drove this project to transform into an initiative to use negotiation and cooperation to collect and compare historical data about educational computing projects.

Key words: Distributed computing; Academic computing; Historical case studies.

\section{INTRODUCTION}

The goal of improving the viability of educational computing projects by identifying and disseminating effective strategies has historically been a common enterprise (McClintock, 1986; Taylor, 1980). However, when personal desktop computers became common in the early 1980s, pressures from business and government resulted in more intense efforts to determine what had gone wrong in the past and what could be done to insure future efforts would be successful. The report POWER ON: New Tools for 
Teaching and Learning (OTA, 1988) described how the number of computers in education had been steadily increasing, but that their numbers and quality were still too low for them to have a large impact across the curriculum at that time. The authors of that report relied upon beliefs about the problems in past initiatives to support the following recommendations for future efforts:

- Expanding the amount and capability of technology in schools to increase student access;

- Providing training and support for teachers;

- Encouraging innovation and improvement in educational software; and

- Supporting research, development, demonstration, and evaluation, with emphasis on ties between research and the classroom. (OTA, 1988, p. 4)

These broad suggestions were based upon an extensive analysis of reports from older projects and highlighted problems that thwarted previous efforts. Addressing the issues would certainly be prerequisites for insuring the success of new educational computing initiatives. However, it was increasingly clear that new educational computing initiatives would be using networked computing environments and software capable of accessing and manipulating many widely distributed databases of linked text, graphics, sound and video (Molnar, 1990). This would represent a revolution in the computing paradigm like that which occurred in the shift from mainframe computers to microcomputers in the 1970s and 1980s. Would it be enough for new educational computing projects to address the flaws in earlier projects, or would they fail due to unforeseen problems that were a function of the new computing paradigm?

Personal experience with creating the educational computing project ESCAPE, an information system for engineers implemented within a distributed computing environment at Purdue University in 1989-1990 convinced this researcher that there would be new problems that would threaten the success of educational computing projects in distributed computing environments (Hopper, LeBold, \& Feghali, 1991). This was the motivating force behind the decision to undertake a study to explore how problems that characterized previous educational computing initiatives became intertwined with unique new problems that were a function of distributed computing (Hopper, 1993). 


\section{METHODS}

It was critical to gather information from the few existing pockets of expertise in using distributed computing environments for educational projects. Academic computing organizations at Purdue University, Brown University (Meyrowitz, 1986; Yankelovich, Meyrowitz \& VanDam, 1985) and the Massachusetts Institute of Technology (Arfman \& Roden, 1992; Champine, 1991; Lerman, 1987) had invested in creating distributed networked computing systems beginning in the late 1970s. The educational projects created using those environments were ending and ready to be analyzed with hindsight by their participants by 1990. This study focused on courseware projects rather than systems software, programming languages or authoring tools.

The following research questions guided this study:

- What were the relationships between the educational, technical, and organizational contexts of courseware?

- What were the educational goals of the courseware?

- Did the goals focus more upon discipline-oriented outcomes, or upon broader outcomes for the learners?

- What educational considerations influenced technical decisions about courseware?

- What were pragmatic technical issues that emerged during courseware projects?

- What were key technical characteristics that determined the viability of courseware?

- What were the relationships between the roles, tasks, and the timing of tasks?

The following projects, organizations and participants were the focus of this study:

Project: ESCAPE (HyperCard, HyperNews, Gohper, WWW)

Organizations: Educational Research and Information Systems, Freshman Engineering,

Purdue University

Participants: Thomas Putnam, William LeBold, Robert Lawler, Mary Hopper, Sherman Ward, Judy Rehwinkel, Robert Tillotson

(LeBold, Hopper \& Feghali, 1991)

Project: Context32 (Intermedia, StorySpace, WWW)

Organizations: Institute for Research and Information Scholarship, Brown University

Participants: Nicole Yankelovich, Paul Kahn, George Landow

(Beeman, et.al., 1987; Landow, 1989) 
Project: TODOR (Athena, BLOX) \& Mechanics 2.01 (Athena, cT)

Organizations: Athena and Academic Computing and Aero/Astro Engineering, Massachusetts Institute of Technology

Participants: Gregory Jackson, Naomi Schmidt, Janet Daly, Anne Lavin, Laurence Bucciarelli

(Murman, LaVin \& Ellis, 1988; McCune, 1989; Murman, 1987; Trilling, 1988) (Bucciarelli, 1992; Bucciarelli \& LaVin, 1992)

Project: Physical Geology Tutor (Athena, AthenaMuse)

Organizations: Center for Educational Computing Initiatives and Civil Engineering, Massachusetts Institute of Technology

Participants: Steven Lerman, Benjamin Davis, Evelyn Schlusselberg, Pat Kinnicutt (Einstein, 1991; Kinnicutt, 1992)

The main data collection strategy used in the study was in-depth interviews with key developers and managers of the organizations that supported the projects (Marshall \& Rossman, 1989, p. 94). The researcher's personal conversations with participants illuminated events and relationships that were critical during courseware development, but were not frequently or freely written about in published accounts. Every interview was audio or video taped. Once the tape was transcribed, interview logs were divided into segments based on topics of conversations.

A continuous process of literature review was essential to continue apace of numerous references provided by participants. The accumulated documents were used extensively to conduct "historical analysis" (Borg and Gall et al, 1989, p. 403). This allowed triangulation between more accounts than were available through interviews alone.

The passages from interviews were combined with selected passages from the project director's and producer's other published reports and publications to result in the total passages that were included in the original research report. The total amount of taped data collected during interviews, and the relative proportion of transcribed passages from those tapes that were actually included in the original research report are represented in Table 1 below. The complete data collection process resulted in a series of historical case studies that captured participant's expert recollections, insights and hind sights about the development of the educational projects in early distributed computing environments. 
Table 1. Data Collected, Transcribed and Included in the Study

\begin{tabular}{cccccc}
\hline Projects & $\begin{array}{c}\text { Hours of } \\
\text { Taped } \\
\text { Interviews }\end{array}$ & $\begin{array}{c}\text { Passages } \\
\text { Transcribed }\end{array}$ & $\begin{array}{c}\text { Passages in } \\
\text { Report from } \\
\text { Interviews }\end{array}$ & $\begin{array}{c}\text { Passages in } \\
\text { Report from } \\
\text { Publications }\end{array}$ & $\begin{array}{c}\text { Total } \\
\text { Passages } \\
\text { in Report }\end{array}$ \\
\hline ESCAPE & 9.5 (Video) & 50 & 22 & 60 & 82 \\
Context32 & 3.5 (Audio) & 23 & 9 & 45 & 54 \\
TODOR/201 & 6.0 (Audio) & 30 & 22 & 35 & 57 \\
Geo. Tutor & 4.75 (Audio) & 26 & 19 & 20 & 39 \\
\hline Total Data & 23.75 & 129 & 72 & 169 & 232 \\
\hline
\end{tabular}

\section{RESULTS}

Triangulation among data obtained through interviews and analysis of documents allowed this researcher to determine that each of the projects were characterized by simultaneous attention to a consistent set of key factors across their educational, technical and organizational contexts. The major factor in the success of courseware initiatives was the degree to which they found ways to address their educational and technical requirements within the constraints of the organizational considerations.

\subsection{Educational Context}

The participants in this study were first and foremost concerned with the educational nature of their endeavor. All of the projects studied began with goals for providing both improved representations of the discipline and increased learner involvement. Successful projects tried to provide a significantly different experience than could be provided through more traditional means. Participants in this study of successful courseware endeavors developed explicit rationales describing how the computer based tools met their educational goals in ways that could not be done in any other way as effectively, efficiently or cheaply. An orientation towards thoughtful implementation of technology based on its ability to serve broader, preexisting educational goals was a predominant theme throughout the projects studied. This careful attention to the "educational" nature of computing projects exerted a powerful influence upon technical and organizational decisions.

\subsection{Technical Context}

Critical technical characteristics of software included appropriate functionality, usability for interaction and creation, and adaptability for the change inherent in distributed computing environments. 
Balancing these issues with the educational goals at hand took a great deal of effort and forethought by those closely associated with projects. To forget about technical requirements was to ensure the limited success of a project. However, another danger was to become so concerned about solving technical problems that sight was lost of the educational goals.

The selection of software was primarily based upon its ability to represent a particular aspect of the discipline at hand. Then regardless of the types of software that projects used, how well the software supported the creation of courseware and the interaction of users became a major consideration. According to the degree of emphasis on learner oriented goals, the degree of usability for the author or the learner were also important attributes that were considered as selection criteria before the package was adopted. In cases where ease of use was not considered ahead of time, it became a major problem once the courseware was under construction (Hopper, 1994).

The adaptability of courseware so as to preserve availability by accommodating change was a significant issue. For example, the Context32 project was deeply affected by the lack of adaptability of the Intermedia software. Despite the immense amount of work and educational thought that went into creating Intermedia, it's lack of adaptability ultimately caused it's demise. In the following passage, Paul Kahn, then director of the Institute for Information and Scholarship, portrayed the adaptability issues that brought the conclusion of the Intermedia project:

"The news has been both good and bad. The good news has been that this ambitious design has been accomplished without special hardware or operating system software. Pre-3.0 Intermedia had required a version of the UNIX operating system for the IBM RT PC that was not generally available. It had also been built on a layer of software and a database management system that presented formidable licensing constraints for distribution outside of Brown University. All of these constraints had been overcome in Intermedia 3.0, and as a result over 200 licensed copies were distributed in 1989 and 1990. However, the bad news has been that, despite it general availability since 1988, Apple's UNIX has never been the operating system of choice for most Macintosh users. The cost of a Macintosh operating system is included in the price of the computer. A/UX must be purchased separately and has always required significantly more RAM (at a time when memory was very expensive) and more hard disk than the Macintosh operating system. Running A/UX added between $\$ 2,000$ and 4,000 to the cost a Macintosh II workstation. In addition, the kind of a high-speed transparent network file access that makes the collaborative features of Intermedia possible require Ethernet 
hardware. Up through the summer of 1990 Intermedia had been one of the few applications that ran under A/UX and one of only a handful that made use of the Macintosh Toolbox to present a graphical user interface. In the summer of 1990, Apple Computer made changes to A/UX version 2.0 that made it incompatible with Intermedia. By that time, support for further development of Intermedia had ended. To run Intermedia, users have had to maintain or locate a version of A/UX that is no longer supported by Apple." (Launhardt \& Kahn, 1991, pp. 13-14)

The Intermedia project officially ended in 1991 while this study was taking place, and George Landow was porting Context32 to Eastgate System's Story Space hypertext software. This resulted in the loss of the functionality of collaboration over a network, but it also resulted in the project becoming widely available. Ultimately, availability was the goal.

Projects that used the Athena computing environment at MIT also experienced problems with adaptability. The biggest problems were due to incompatibilities in X-Windows System 10 and System 11 (Stewart, 1989). In fact, the TODOR project included in this study was one of the few that survived the changes, and that survival was attributed to the presence of a member of the Athena development team on that project.

\subsection{Organizational Context}

The factors in the organizational contexts were far more critical than had been anticipated prior to the initiation of this research. The reasons for this were most salient for projects at MIT. The educational projects that used Athena needed to cope with continuous change and expansion of the underlying system, and thus also needed to change in order to survive. The discontinuation of either delivery or modification marked the end of a project because courseware quickly fell from disuse to unusable. To insure that the project was used, updated and expanded, authors needed to continually find ways to acquire critical resources. The dilemma was to find ways both inside and outside of traditional organizational structures to overcome the inherent lack of existing support for courseware development in academic settings. Successful projects recast learners as authors, while authors were recast as managers of educational, technical and organizational factors that needed to be continuously balanced (Hopper, 1997).

In summary, each project's attempts to reach unique discipline and learner oriented goals afforded by new computing capabilities led to unforeseen technical challenges that became intertwined with issues related to traditional organizational structures for distributing and managing human, technological, and financial resources in academic organizations. When 
educational decisions presented technical challenges, successful projects developed organizational structures to address the challenges.

\section{DISCUSSION}

The results of this study yielded valuable advice about how to implement educational projects in distributed computing environments and was applicable to the World Wide Web as it emerged. However, there was also another important outcome of this study. Later reflections by the author and feedback from the participants made it apparent that it would be valuable to systematically gather and integrate increasingly elaborate, detailed and older data about educational computing projects. The goal of this would be to document and understand the complex historical contexts that led to the success of ongoing projects across multiple generations of technology.

Projects increasingly have a cyclic nature due to a complex interaction of broader technology and internal funding cycles. Mature projects in this study had gone through multiple generations of development. To fully understand them, it was necessary to gather extensive information about the project beyond the current iteration. It was sometimes even difficult to establish clear boundaries between projects. Finally, some projects were designed to achieve transient goals rather than long-term continuation, so the question of success for these projects was more one of impact than survival. The best way to determine their success was through establishing the influence and connections they had to other projects.

A significant body of aggregated information about educational computing projects is critical for tracking the evolution of individual projects and the relationships among them over multiple generations. Aggregating information can start with sets of data like that obtained from catalogs, summaries or reports. Then it is essential to use a weighting scheme to determine when to pursue targeted documentation such as published findings. Finally, it is critical to include detailed accounts from interviews and internal documents obtained through case studies. Unfortunately, the level and amount of data that can be collected by individual researchers varies directly with their level of access to projects. This presents a dilemma for large-scale investigations of the history of educational computing. Luckily, the most detailed data and accurate insights are best obtained from those who worked on the project, so a productive approach is to create ways for the participants themselves to contribute information.

These points have led the original research project reported above to gradually evolve towards emphasizing negotiation and cooperation to obtain and include data from the participants in educational computing projects, 
working simultaneously bottom up and top down. The project is thus transforming into a collaborative community resource where project participants can share knowledge. This approach will support an expedition to understand the complex relationships among key factors in the educational, technical and organizational contexts within and between educational computing projects across a variety of disciplines and levels as they change over time. A key component of this approach will also be to advocate ongoing longitudinal data collection and preservation within the projects themselves, and then to document where the project information resides and what it contains so others might use it.

Ever since the original study, computing technology was used to support data collection, analysis and reporting, but the new direction presents a technical challenge that will require a powerful digital environment for storing and integrating information. This parallels developments in a related field. Scholars who study the recent history of science and technology have undertaken digital projects focused on automation and collaboration with living participants. One of the most recognized among these initiatives is the History of Recent Science and Technology (HRST) funded by the Sloan Foundation and centered at the Dibner Institute at the Massachusetts Institute of Technology.

A great hope of the HRST founders was that this website would be used primarily by scientists and engineers, experts in their own fields, who would select most important primary sources and deposit them on the site, compile timelines and bibliographies, add comments, and organize online discussions. Historians working on the project would largely serve as facilitators, helping the primary users to cope with the intricacies of the Web technology. The website itself would serve as the true engine of historical research. (Gerovitch, 2002)

In the future, the original research project that has been the subject of this paper will evolve into an appropriate technical environment to support follow-up and further elaboration about the projects already studied (Mitchell \& Dertouzos, 1997). Projects that are closely related to those already studied will be added. This might include PLATO from the University of Illinois (Alpert \& Bitzer, 1970) as well as cT and Andrew at Carnegie Mellon University (Arms, 1988, 1990). Most importantly, an investigation of the development of the computer language Logo will serve as the primary pilot for the next phase of this research (Papert, 1980). It is an excellent project to investigate due to it's robust and ongoing success, it's durability over many generations of computing paradigms, it's focus on a wide range of audiences from children to adult, and most importantly, it's great success in the international arena. Data about how and why it has 
succeeded around the globe will be sought from people associated with the Logo community on every continent.

\section{CONCLUSION}

This paper has described how a project to study the factors that influence success in educational computing projects evolved from historical case studies carried out in the early 1990s to the point of transition where it is today. While the long-term goal of the project continues to be improving the viability of educational computing projects by identifying and disseminating effective and sustainable strategies, how to go about it has evolved greatly. Specific limitations encountered in the original study's methodology drove the project to transform into using negotiation and cooperation for collecting and comparing broader and more in-depth historical data. This process may be a first step towards understanding where the field of educational computing has been, how successful it has been and why. Ultimately, this project could serve as a disciplinary memory for the uses of computers in education. Having such a memory broadly available for analysis could potentially make it easier to determine ways to go forward with both existing and new projects more successfully in the future.

\section{REFERENCES}

Alpert, D. and Bitzer, D., 1970, Advances in computer-based education. Science 167: 15821590

Arfman, J.M. and Roden, P., 1992, Project Athena: Supporting distributed computing, IBM Systems Journal 31(3): 550-563.

Arms, W. Y., 1988, Andrew Plus: Personal Computing at Carnegie Mellon, Carnegie Mellon University, Pittsburgh, PA.

Arms, W. Y., 1990, Reflections on Andrew, EDUCOM Review, 25(3): 33-39.

Beeman, W. O., Anderson, K. T., Bader, G., Larkin, J., McClard, A. P., McQuillan, P. and Shields, M., 1987, Intermedia: A Case Study of Innovation in Higher Education. Providence, Brown University Office of Program Analysis, Institute for Research in Information and Scholarship, Providence, RI

Borg, W. R. and Gall, M. D., et al., 1989, Educational Research: An Introduction, 5th ed., Longman Publishing, New York, NY.

Bucciarelli, L., 1992, Results of Survey of Student use of Athena-Based Problem Solutions, unpublished raw data, MIT, Cambridge, MA.

Bucciarelli, L. and LaVin, A. R., 1992, 2.01: The mechanics of solids, and Athena: A conversation with Larry Bucciarelli, Athena Insider: The Academic Computing Services Newsletter, 3 (1): 6-11.

Champine, G. A., 1991, MIT Project Athena: A Model for Distributed Campus Computing, Digital Press, Cambridge, MA. 
Einstein, H., 1991, Engineering Geology Educator, in C. Avril, ed., Windows on Athena: Vol. 2: Project Athena's Curriculum Development Projects...And Beyond, MIT, Cambridge, MA.

Gerovitch, S., 2002, Toward an Interactive History of Science and Technology: Reflections on the Dibner/Sloan Web Project, paper presented at the LXV plenum of the Russian National Committee of the History and Philosophy of Science and Technology, Moscow.

Hopper, M. E., LeBold, W. K., and Feghali, A. A., 1991, A hypermedia-based problemsolving approach to engineering, learning, working, and playing, in Proceedings of the 1991 Frontiers in Education Conference, pp. 73-78.

Hopper, M.E., 1997, The Role of Learners in the Construction of Successful Courseware Projects in Distributed Academic Computing Environments, round-table presentation at the Annual Meeting of American Educational Research Association, Advanced Technologies for Learning (SIG-ATL), Chicago, IL.

Hopper, M. E., 1994, Usable software in advanced educational computing projects, ACM SIGGRAPH Computer Graphics, 28(1): 46-48.

Hopper, M.E., 1993, Expert's views about key issues for courseware development in advanced computing environments [Abstract], in H. Maurer, ed., Proceedings of EDMEDIA 93 - World Conference on Educational Multimedia and Hypermedia, p. 607.

Hopper, M. E., 1993, Educational Courseware Production in Advanced Computing Environments, unpublished doctoral dissertation, Purdue University, West Lafayette, IN.

Jackson, G., 1991, Conclusion: Project Athena in the evolution of academic computing at MIT, in C. Avril, ed., Windows on Athena: Vol.2: Project Athena's Curriculum Development Projects...And Beyond, MIT, Cambridge, MA.

Kinnicutt, P., 1992, Engineering Geology Tutor 1.32/1.38 Questionnaire General Comments, unpublished data, MIT Department of Civil Engineering, Cambridge, MA.

Launhardt, J. and Kahn, P., 1991, The Educational Uses of Intermedia (Tech. Rep. No 91-2), Brown University Institute for Research in Information and Scholarship, Providence, RI.

Landow, G. P., 1989, Course assignments using hypertext: The example of Intermedia, Journal of Research on Computing in Education, 21: 349-365.

LeBold, W. K., Hopper, M. E., and Feghali, A. A., 1991, A hypermedia solution to a hyper problem: Personalized computer engineering career system, in Proceedings of the 1991 ASEE-IEEE Annual Conference (Educational Research and Methods Division), pp. 482488.

Lerman, S., 1987, Mission and Goals for Project Athena After June 1988, MIT Project Athena, Cambridge, MA.

Marshall, C. and Rossman, G. B., 1989, Designing Qualitative Research, Sage Publications, Newbury Park, CA.

McClintock, R., 1986, Into the starting gate: On computing and the curriculum, Teacher's College Record, 88(2).

McCune, J. E., 1989, The TODOR workshop: Computer-enhanced teaching of fluid mechanics, in C. Avril, ed., Windows on Athena: Project Athena's Curriculum Development Projects, Project Athena, Cambridge, MA.

Meyrowitz, N., 1986, Intermedia: The architecture and construction of an object-oriented hypertext/hypermedia system and applications framework, ACM SIGPLAN Notices 21(11): 186-201.

Meyrowitz, N., 1991, Hypertext - does it reduce cholesterol, too? in Nyce, J. and Kahn, P. eds., From Memex to Hypertext: Vanevar Bush and the Mind's Machine, Academic Press, pp. 287-318. 
MIT Committee on Academic Computation for the 1990's and Beyond, 1990, Computingfor Education at MIT: Final Report, MIT, Cambridge, MA.

Mitchell, W. J. and Dertouzos, M. L., 1997, MIT Educational Technology Council Report, MIT, Cambridge, MA.

Molnar, A., 1990, Computers in education: A historical perspective of the unfinished task, THE Journal 18(4): 80-83.

Murman, E. M., 1987, Computer Enhanced Curriculum For Fluid Mechanics: A Progress Report, MIT, Cambridge, MA.

Murman, E. M., LaVin, A. R. and Ellis, S. C., 1988, Enhancing Fluid Mechanics Education with Workstation Based Software, AIAA Paper 88-0001 Paper presented at the AIAA 26th Aerospace Sciences Meeting January 11-14, 1988, Reno, Nevada.

Office of Technology Assessment, 1988, Power on!: New Tools for Teaching and Learning, Congress of the U. S., Office of Technology, Washington, DC.

Papert, S., 1980, Mindstorms: Children, Computers, and Powerful Ideas, Basic Books, NY.

Stewart, J., 1989, How to manage educational computing initiatives-lessons from the first five years of Project Athena at MIT, in E. Barrett, ed., The Society of Text: Hypertext, Hypermedia and the Social Construction of Information, MIT Press, Cambridge MA, pp. 284-321.

Taylor, R. P. (Ed.), 1980, The Computer in the School: Tutor, Tool, Tutee, Teachers College Press, New York, NY.

Trilling, L., 1988, AERO/ASTRO Students' Reaction to the Use of Athena Materials in Fluid Mechanics, MIT Department of Aeronautics and Astronautics, Cambridge, MA.

Yankelovich, N., Meyrowitz, N. and VanDam, A., 1985, Reading and writing the electronic book, IEEE Computer, 18(10): 15-30. 